\title{
Experiment Study on Coal Roadways Roof Monitoring Based on the Pre-stretched Optical Fiber Lay out at Fixed-points
}

\author{
Tao Hu ${ }^{1,}$ *, Su Bu ${ }^{2, ~ *, ~ G Y ~ H o u ~}{ }^{1}$, Yan Wang ${ }^{3}$, Ziyi $\mathrm{Hu}^{3}$, Zixiang $\mathrm{Li}^{1}$, Jinping Liang ${ }^{1}$, Yuliang Zhou ${ }^{1}$, \\ Haoyong Jing ${ }^{1}$
}

${ }^{1}$ School of Mechanics and Civil Engineering, China University of Mining \& Technology, Beijing, China

${ }^{2}$ School of Laws and Humanities, China University of Mining \& Technology, Beijing, China

${ }^{3}$ Shandong Energy Group CO., Ltd., Jinan, China

Email address:

tbp150602027@student.cumtb.edu.cn (Tao Hu), cumtblawbusu@163.com (Su Bu)

${ }^{*}$ Corresponding author

\section{To cite this article:}

Tao Hu, Su Bu, GY Hou, Yan Wang, Ziyi Hu, Zixiang Li, Jinping Liang, Yuliang Zhou, Haoyong Jing. Experiment Study on Coal Roadways Roof Monitoring Based on the Pre-stretched Optical Fiber Lay out at Fixed-points. International Journal of Oil, Gas and Coal Engineering. Vol. 8, No. 5, 2020, pp. 103-115. doi: 10.11648/j.ogce.20200805.12

Received: September 24, 2020; Accepted: September 30, 2020; Published: October 7, 2020

\begin{abstract}
The safety monitoring of coal roadways roof is the key to prevent roof accidents and ensure coal mines safety. However, the monitoring blind zones caused by traditional methods is one of the main reasons of frequent roof accidents. To ensure the safety of coal mines production, a novel roof monitoring method is proposed in this paper, which is based on the distributed optical fiber sensing (DOFS) and the pre-stretched optical fiber layout at fixed points (POFLF). The research of this approach has been carried out through analysis of DOFS optical fiber strain monitoring and POFLF theory, and with the help of indoor optical fiber strain experiment. Finally the approach was applied in the field monitoring of a coal roadway roof. Aforementioned verified the optical fiber strain distribution not only accurately indicate the roof settlement range, but also qualitatively and quantitatively demonstrate the roof subsidence displacement. The feasibility and validation of the approach as a supplementary or auxiliary resorts in roof safety monitoring were confirmed. The research in this paper not only has important reference significance for the safety monitoring of coal roadways roof under similar geological and production conditions, but be of helpful for improving the coal mine safety as well.
\end{abstract}

Keywords: Coal Roadway Roof Monitoring, Distributed Optical Fiber Sensing, Brillouin Optic Time-domain Reflectometry, Pre-stretching Optical Fiber Layout at Fixed-point, Quantitative Characterization

\section{Introduction}

Coal roadway roof collapse accidents are the most common and frequent accidents. According to statistics from the State Administration of Coal Mine Safety (SACMS) for more than ten years, coal mine roof accidents accounted for $51.2 \%$ of the total number of coal mine accidents, while the death toll caused by coal mine roof accidents accounted for $36.5 \%$ of the total death toll [1]. And the roof collapse of coal roadway is one of the main causes of casualties, equipment damage and production losses in coal mines [2]. Therefore, preventing and reducing coal mine roadway roof accidents is the primary guarantee and prerequisite for coal mine safety production. Practice has proved that the roof collapse accident is mainly caused by excessive roof subsidence and layer separation [3]. Because roof subsidence is the direct manifestation of roof strata separation, roof subsidence displacement monitoring has good early warning and alarm function for roof disaster. Therefore, it is the most direct and effective prevention and monitoring measures to embed roof separation instruments, extensometers or inclinometers in roof for displacement monitoring, those are not only widely used by coal mines in the world, but also a mandatory requirement of coal mine safety regulations in various countries [4-7], For example [8] in the UK and Canada, two 
anchor extensometers are installed every $20 \mathrm{~m}$ in roadways and all intersections underground coal mines; in South Africa, an extensometer is installed every 20 anchorage points; China stipulates that a roof separation instrument is installed every $50 \mathrm{~m}$ in the coal roadway of ordinary bolt supporting. However, up to now, coal mine roof accidents still cannot be effectively curbed, there are two important reasons, one is that the current application of sensors are point sensors, the distance of sensors interval is large; the other is the monitoring mode is point by point, inevitably there are monitoring blind areas and monitoring leakage points between sensors, Which resulted in the monitoring of roof separation and displacement data are too scarce to correctly reflect the roof deformation characteristics, therefore, many of the corresponding early warning and the alarm effect were ignored. The cruel reality and severe coal mine safety production situation make it very urgent and imperative that a new distributed monitoring technology without monitoring blind area and monitoring omission point must be explored to effectively monitor the safety of coal roadway roof.

It is only the Distributed optical fiber sensing (DOFS) technology which emerged in the 1980s is just the kind of techniques the coal mines need utmost urgently. It can make up for the shortcomings of traditional monitoring technology with its distributed, long-distance and large-scale continuous strain monitoring features. Moreover, the medium of the sensing and transmission of DOFS is the optical fiber, which also has the following intrinsic advantages: passive (all dielectric); anti-electromagnetic interference; high temperature performance; explosion proof; corrosion and oxidation resistance; light weight, small size and convenient layout. Therefore, DOFS breaks through the limitations of traditional mechanical and electronic sensors and has been widely used in the various structure health monitoring [9-10], especially in the civil tunnels [11-12] and roadways of underground metalliferous mine [13-14]. Unfortunately, there is seldom research reported about coal roadways roof monitoring based on DOFS in scientific papers nowadays before.

In this paper, a new approach based on DOFS combined with pre-stretched optical fiber layout at fixed-points (POFLF) is proposed for realizing the distributed settlement monitoring of coal roadways roof. Through the theoretical analysis and laboratory experiments of this approach, the quantitative characterization of roof displacement by optical fiber strain is carried out, and it is successfully applied to the field monitoring of a coal roadway roof. The research in this paper is of significant reference to improve the safety management of coal roadways roof and promote the coal mine safety production in China.

\section{Distributed Optical Fiber Sensing Technology (DOFS)}

DOFS uses low-cost telecom-grade optical fiber cable as the inherent sensing material for sensing and transmission purposes. DOFS uses the laid one-dimensional optical fiber as the sensor to monitor the changes of various physical measurands along the axial direction of the optical fiber according to the optical properties of the scattered light, such as temperature, strain and vibration. According to the layout principle of sensors, it is divided into point sensors, quasi distributed sensors and fully distributed sensors [15]; according to the sensing principle [16], it is mainly divided into: Distributed Vibration Sensing technology (DVS or DAS) based on Rayleigh scattering, Distributed Temperature Sensor (DTS) based on Raman scattering principle and Distributed Temperature / Strain Sensor (DTSS) based on Brillouin scattering. For our research purpose, the distributed strain measurement technology of Brillouin optical time domain reflectometry (BOTDR) is used in this study. The novelty of this new technology is that it can simultaneously sense tens of kilometers of fiber for continuous distributed strain measurement, providing a relatively cheap but efficient monitoring system.

BOTDR has been widely used with its advantage of single end test. It is a system that uses spontaneous scattering light to measure the return time of optical pulses entering the fiber under Test (FUT) and the intensity of scattered light at each sampling point. By analyzing the measured time and strength, BOTDR calculates the physical quantities of distribution, such as temperature and strain. The basic configuration of BOTDR is shown in figure 1 .

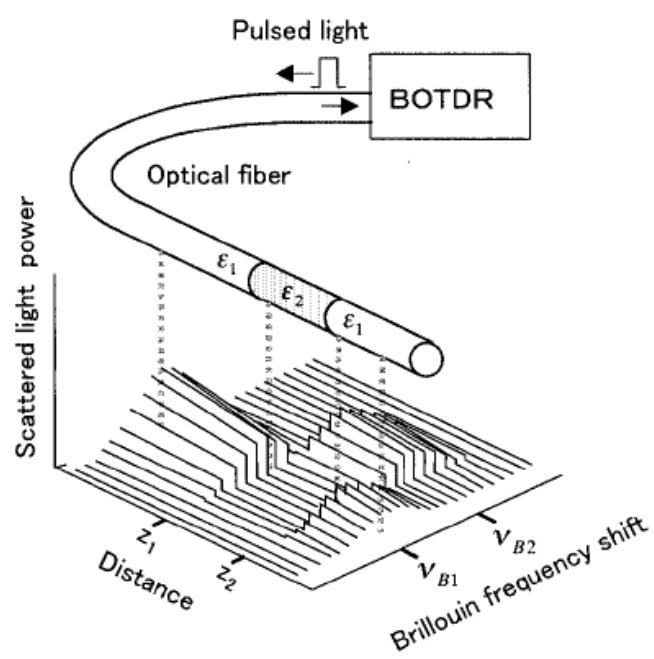

Figure 1. Schematic diagram of strain monitoring of BOTDR.

In the measuring of BOTDR [17], the relationship between the frequency shift and the longitudinal strain and temperature changes in the core / cladding can be approximately expressed by a linear function, as shown in formula (1):

$$
v_{B}(T, \varepsilon)=v_{B}\left(T_{0}, \varepsilon_{0}\right)+C_{T}\left(T-T_{0}\right)+C_{\varepsilon}\left(\varepsilon^{-} \varepsilon_{0}\right),
$$

Where, $v_{B}(T, \varepsilon)$ is the optical frequency shift at temperature $T$ and strain $\varepsilon ; \nu_{B}\left(T_{0}, \varepsilon_{0}\right)$ is the Brillouin frequency shift at the initial temperature $T_{0}$ and initial strain $\varepsilon_{0}$ of the optical fiber; $C_{T}$ is the temperature coefficient of the optical fiber; $C_{\varepsilon}$ is the strain coefficient of the optical fiber 
According to the strain measuring theory of BOTDR, the data obtained from BOTDR test are the strain values of each sampling point along the axial direction of the optical fiber. By integrating the strain values along the axial length of the optical fiber, the axial tension amount or compression amount of the optical fiber can be obtained.

$$
\delta=\int_{z_{1}}^{z_{2}} \varepsilon(z) d z
$$

Where, $\delta$ is the compression or stretching amount of optical fiber between $Z_{1}$ and $Z_{2} ; \varepsilon(z)$ is the strain value of each sampling interval between $Z_{1}$ and $Z_{2}$. According to different monitoring requirements, there are the following sampling intervals to a BOTDR instrument: $1 \mathrm{~m}, 0.5 \mathrm{~m}, 0.2 \mathrm{~m}$, $0.1 \mathrm{~m}, 0.05 \mathrm{~m}$.

Similarly, according to the definition of strain, it can be seen that when the optical fiber is fixed between $Z_{1}$ and $Z_{2}$, the optical fiber will deform uniformly in a straight line between the fixed points, and the fiber strain $\varepsilon_{\text {between the }}$ fixed points is considered as uniform strain. Assuming that the length of optical fiber between $Z_{1}$ and $Z_{2}$ is $L$, then:

$$
\varepsilon=\frac{\delta}{L}
$$

Based on the formula (1) - (3), the strain, deformation amount and the length of the fiber can be obtained. According to the length of the fiber after deformation, other geometric parameters of the fiber deformation can be calculated by using the geometric principle.

\section{POFLF Techniques on the Roof of Coal Roadways}

In China, more than $90 \%$ of the coal mines adopt the longwall mining technology [18-19]. The longwall mining process usually includes two gateroads, which are called haulage gateroad (air-intake gateroad) and air-return gateroad. The mining gateroads account for more than $80 \%$ of the total roadway footage in coal mines [20]. The common roadways in the long wall mining are mainly rectangular coal roadways, their roof and two sides' walls are all composed of coal. For ordinary mining coal roadway, the roadway will be abandoned after the working face passing through. The supporting principle is that only primary bolt supporting is needed before the working face passes through to keep the roadway stable. After mining, the roof must collapse as soon as possible to recover coal and prevent gas accumulation to form gas accidents [20].

Therefore, the secondary or multiple support in civil tunnels or metal mine roadways should be avoided as far as possible in coal roadways, such as reinforced concrete precast segment support, secondary shotcrete lining, etc. It is very clear that the roof surface of the coal roadways is not smooth and neat, and it mostly present discontinues broken coal rocks and irregularly unsteadily fractured roof surface due to the original sedimentary geological, tectonics fracture conditions and high overburden stress. With the cutting effect of broken coal rocks and loosening effect of irregular unsteadily roof strata, the optical fiber cables cannot be stick to the roof surface or imbedded in the failure coal roof along the roadway strike. It is imperative and urgent to explore a method of optical fiber layout in line with this worse situation and condition of coal roadway roof.

Because the role of bolts supporting is to keep the stability of anchorage body composed of bolts, anchor cables, surrounding rock and so on; and the main function of anchor cables is to suspend the unstable part of lower rock layers on the upper stable rock layers. The displacement change of rock bolts (or anchor cables) not only reflects the settlement displacement of anchorage body, but also reflects the separation change of roof strata. Therefore, the optical fiber cables are laid out via the existing bolts on the roof, it not only can distributed monitor the roof displacement, it can avoid the optical fiber cables being cut by the broken coal rocks owing to a certain distance between the out-end of the rock bolt and the surface of coal roof as well.

\subsection{Pre-stretched Optical Fiber Layout at Fixed-point (POFLF) Technology}

In the relaxation state, the strain of the fiber will not change before the fiber reaches the tension state if the two ends of the fiber are affected by the axial stress of the fiber. Therefore, the optical fiber must be tensioned and straightened before the optical fiber is laid, that is, pre-stretching; the so-called fixed-point layout is based on the principle that two points determine a straight line, and the strain of the sensing optical cable between the fixed points is not affected by the surrounding environment of the optical cable, but only depends on the relative displacement between the two fixed points. When the fixed points move close to each other, the fiber is compressed and the strain is negative; when the fixed points move away from each other, the strain is positive. According to the strain measurement of the sensing optical cable between fixed points, the displacement between adjacent fixed points can be obtained through integral calculation, and then the displacement between each fixed point of the whole sensing optical cables can be obtained.

The displacement range of sensing optical fiber can be increased according to the fixed points spacing $(L)$. For example, when the maximum strain is $15000 \mu \varepsilon$ and $L=1 \mathrm{~cm}$, the measured displacement is $0.15 \mathrm{~mm}$; when $L=100 \mathrm{~cm}$, the measured displacement is $15 \mathrm{~mm}$, and the maximum displacement range is increased by 100 times.

In order to monitor the compressive strain or tensile strain of the sensing optical cable, it is necessary to pre-stretch the sensing optical cables. In this test, the initial strain of the fiber cables were maintained between 2500 and $5000 \mu \varepsilon$. The fixed-point spacing can be determined according to the existing rock bolts or anchor cables layout distance of coal roadways roof. According to the field investigation in the coal mine, the field experiment adopted $100 \mathrm{~cm}$ fixed-point distance, and the maximum tensile length can be measured as 
$15 \mathrm{~mm}$ between fixed points. The POFLF fiber cables on the coal roadway roof can be simply shown as in figure 2 below.

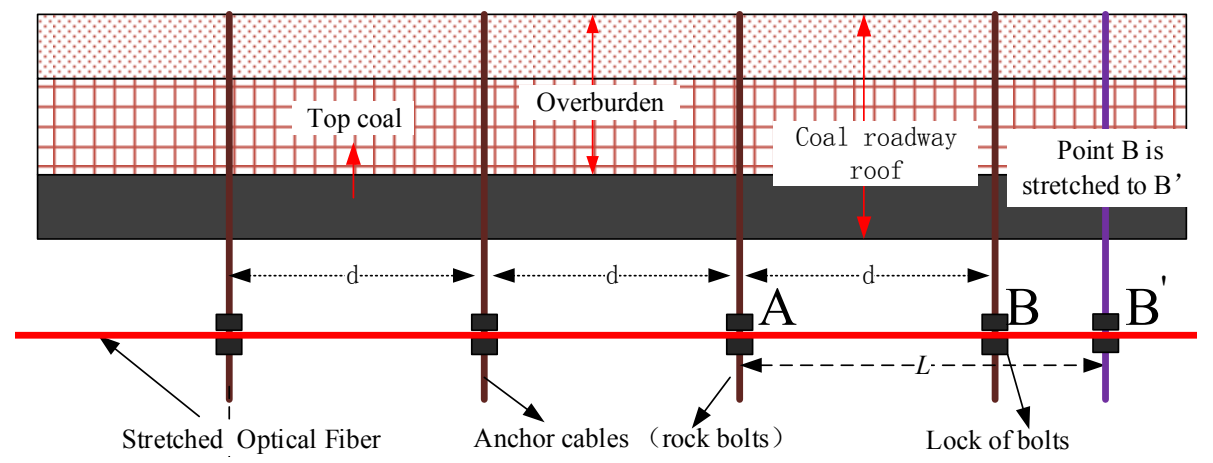

Figure 2. Layout of POFFL on coal roadway roof.

\subsection{Strain Measurement Principle of Pre-stretched Optical Fibers Layout at Fixed-points Horizontally}

Under the gravity influence of overlying strata of roof, the fixed-point of pre-stretched optical fiber laid on the roof of coal roadway has vertical settlement, as shown in figure 3 . Assuming that the red circle dot represents the fixed-point on the roof of the coal roadway, the initial optical fiber $A B$ is horizontally arranged on the coal seam roof of the coal roadway, as shown in the yellow solid line in the figure. There are $n$ fixed points between $A$ and $B$, and the original interval between adjacent fixed points is $d$. When the fiber is deformed from $A B$ to $A B_{1}$, the adjacent fixed points can show uniform deformation of straight-line stretching, as shown by the green dotted line in the figure; it can also present the uneven settlement deformation of irregular polygon, as shown by the black solid line in the figure. Since the roof of coal roadway is mainly affected by gravity after excavation, it can be assumed that the roof of coal roadway only has vertical settlement displacement.

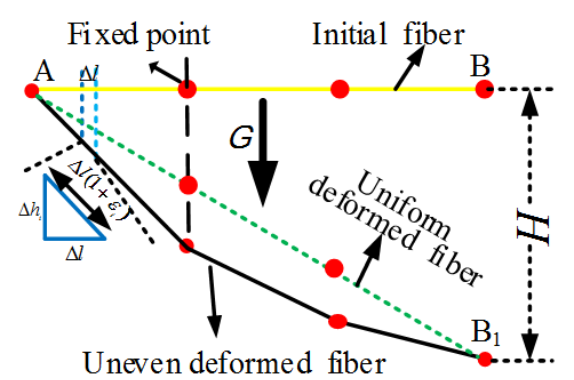

Figure 3. Vertical deformation diagram of POFLF horizontally laid out optical fiber in roofs.

\subsubsection{Uniform Deformation}

As shown in the green dotted line in figure 3 , when the straight line of optical fiber is uniformly stretched to $A B_{1}$, the length of $A B_{l}$ and the maximum settlement displacement $B B_{l}$ of point $B$ can be obtained from formula (6) below:

$$
\left\{\begin{array}{l}
A B_{1}=A B+\int_{A}^{B} \varepsilon(\mathrm{z}) d z \\
B B_{1}=\sqrt{A B_{1}^{2}-A B^{2}} \\
=\sqrt{\left(\int_{A}^{B} \varepsilon(\mathrm{z}) d z\right)^{2}+2 A B \cdot \int_{A}^{B} \varepsilon(\mathrm{z}) d z}
\end{array},\right.
$$

\subsubsection{Uneven Deformation}

As shown by the solid black line in Figure 3, the fixed point of the optical cable is subject to the uneven and irregular settlement of the roof, the same type of settlement occurs at the fixed points of the optical cable. Because the optical cable between any adjacent fixed points is stretched in a straight line due to the restriction of the fixed point, $\mathrm{t}$ the whole optical cables are deformed into polygon $A B_{1}$. From the definition of the sampling resolution $\Delta l$ and the actual test strain $\varepsilon_{i}$ of the sampling point, the deformation length $l_{\Delta i}$ of any sampling interval and the vertical displacement $\Delta h_{i}$ of sampling points in the fiber $A B$ length can be obtained. The maximum vertical displacement $B B_{1}$ of $A B$ is obtained by accumulating the vertical displacements of all sampling intervals in length $A B$.

$$
\left\{\begin{array}{l}
l_{\Delta i}=\Delta l\left(1+\varepsilon_{i}\right) \\
\Delta h_{i}=\Delta l \times \sqrt{\left(\varepsilon_{i}\right)^{2}+2 \varepsilon_{i}} \\
\Delta H=B B_{1}=\Delta l \times \sum_{i=0}^{n} \sqrt{\left(\varepsilon_{i}\right)^{2}+2 \varepsilon_{i}}\left(n=\frac{A B}{\Delta l}\right)
\end{array}\right.
$$

According to formula (4) and formula (5), no matter what kind of deformation of optical fiber appears, the variation of vertical displacement of roof is positively proportional to the change of tensile strain of optical fiber; since the failure range of roof deformation can be obtained from the strain distribution curve of optical fiber, the change of optical fiber strain can qualitatively reflect the settlement deformation degree of coal roadways roof in theory. This characteristic can be used for distributed strain monitoring of coal roadway roof deformation to predict and early warn the occurrence of roof disaster.

\subsection{Deformation Characteristics of Coal Gateroads Roof}

Under the action of high in-situ overburden stress and complex tectonic stress, the roof of coal roadway shows plastic fracture failure, forming different size of plastic broken coal rock blocks, there will be the sporadic caving and overall collapse of broken coal blocks without support. Under the combined support of rock bolts, anchor cables, wire mesh and $\mathrm{W}$ steel belts, although the roof of coal roadway with 
developed joints and fissures will failure and fracture, roof falling is effectively delayed and restricted.

The production practice shows that the roof subsidence deformation can be divided into two forms: sporadic caving of broken coal blocks and overall settlement of large zone of roof coal; sporadic caving of coal blocks forms "point" settlement deformation, and the maximum settlement displacement area is small; overall settlement of large zone of roof coal forms "zone" settlement deformation, and the maximum displacement zone is equivalent to a settlement platform. From the strike section and cross section of roadway, the point type is inverted triangle and the surface type is inverted trapezoid, as shown in figure 4.

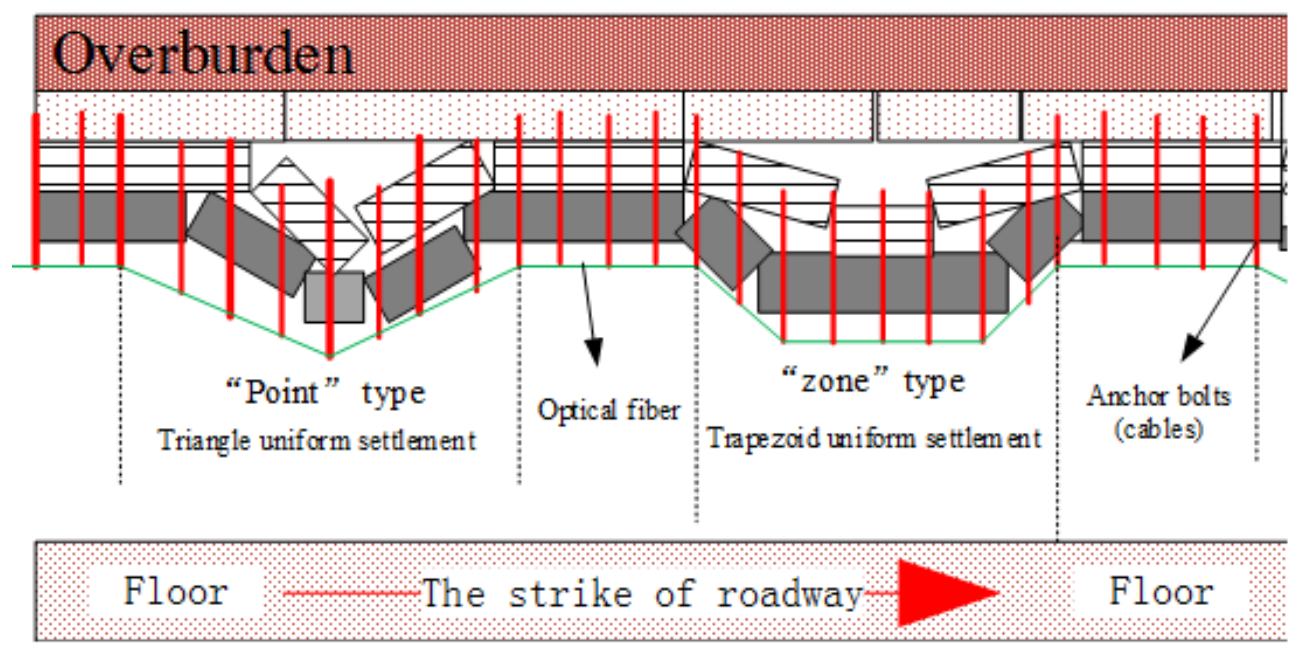

Figure 4. The diagram of the settlement types of coal roadway roof laid out of pre-stretch cables.

\subsection{Quantitative Characterization of Coal Roadways Roof} Settlement Displacement by Optical Fiber Strain

\subsubsection{Sporadic Caving Form of Coal Blocks in a Broken Roof}

It is defined that its main feature is that the zone with the largest settlement displacement is only one anchorage point in

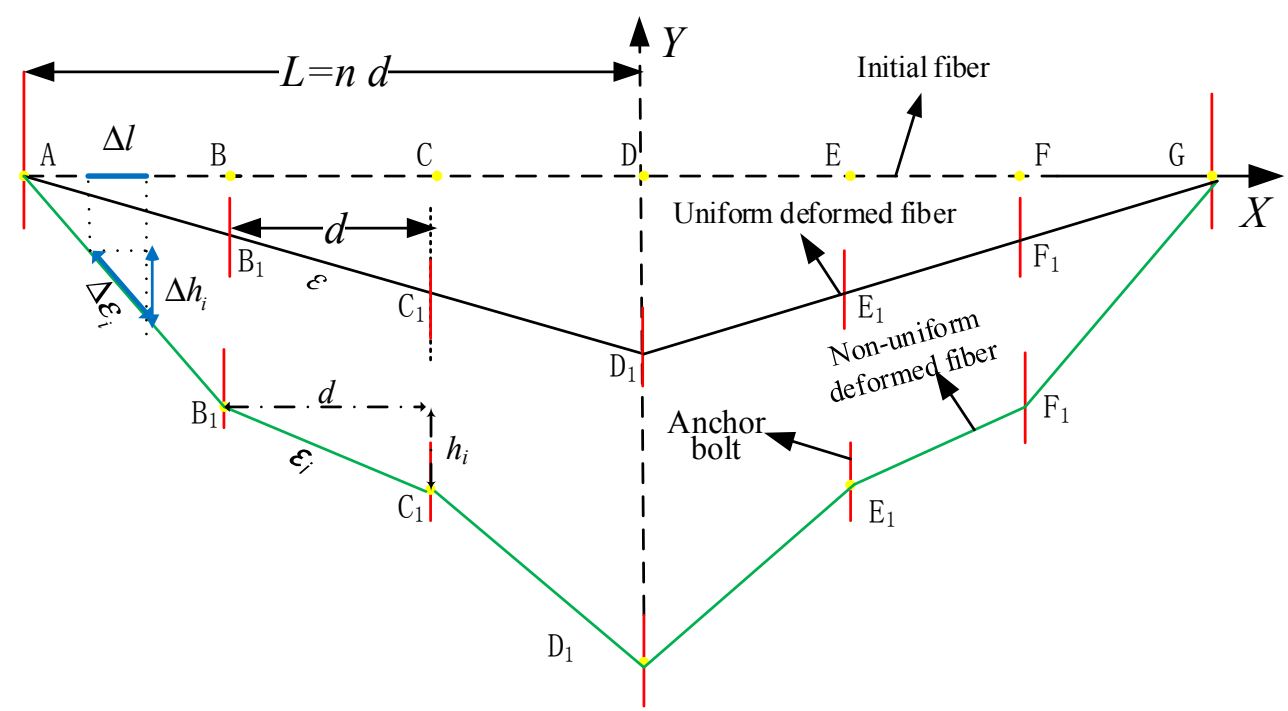

Figure 5. Quantitative characterization of fiber strain of triangle settlement displacement of roof: black solid line indicates that fiber is triangle deformation under uniform linear tension; green solid line indicates that fiber is polygonal deformation with approximate triangle under uneven tension. 1), the optical fiber between the anchors on both sides of the maximum settlement point is stretched in a straight line with uniform deformation, as shown in the black solid line in figure 5. It is assumed that there are $n$ fixed points in the deformation section AD and DG respectively, and the settlement displacement of the No. $n$ fixed point in the middle is the largest, and the overall deformation is an inverted triangle. The displacement of the anchorage point with the largest displacement can be calculated by formula (4) or (5). 2), when the roof settles unevenly, the optical fiber between the fixed points will deform unevenly. The deformation of the roof is triangular polygon. The fiber deformation is shown in the green solid line in figure 5, the displacement of the anchorage point with the maximum displacement on the roof is calculated by formula (5). anchorage point to bult, the settlement displacement of the overall appearance looks like an inverted triangle, which can be divided into two situations: uniform deformation and non-uniform deformation that can be shown as figure 5 below. 


\subsubsection{Large Zone Overall Settlement of Roof}

The main feature is that the maximum settlement position is not a point, but a platform zone. Because the spacing of anchor bolts in the coal roadway is $1000 \mathrm{~mm}$, this paper defines that the platform includes at least two anchor points. From the platform to both sides, the deformation displacement of the roof gradually decreases. Theoretically, there is no optical fiber strain change between the fixed points in the platform. The geometry of the roof deformation is similar to the inverted isosceles trapezoid, and the two waist parts of the trapezoid are strain deformation segments. It can be divided into two situations: uniform deformation and non-uniform deformation that can be shown as figure 6 below.
In the first case, the fiber is linearly stretched by fixed points in the strain deformation section, resulting in uniform strain, as a solid black line shown in figure 6 . The displacement of the platform can be calculated by formula (4) or (5).

The second case is the inhomogeneous deformation of optical fiber. When the uneven settlement of the roof is approximately trapezoidal polygonal, the optical fiber between the $n$ anchors on both sides of the waist is not linear tensile deformation, but polygonal deformation, as a green solid line shown in figure 6 . The maximum displacement of the settlement platform area can be calculated by formula (5).

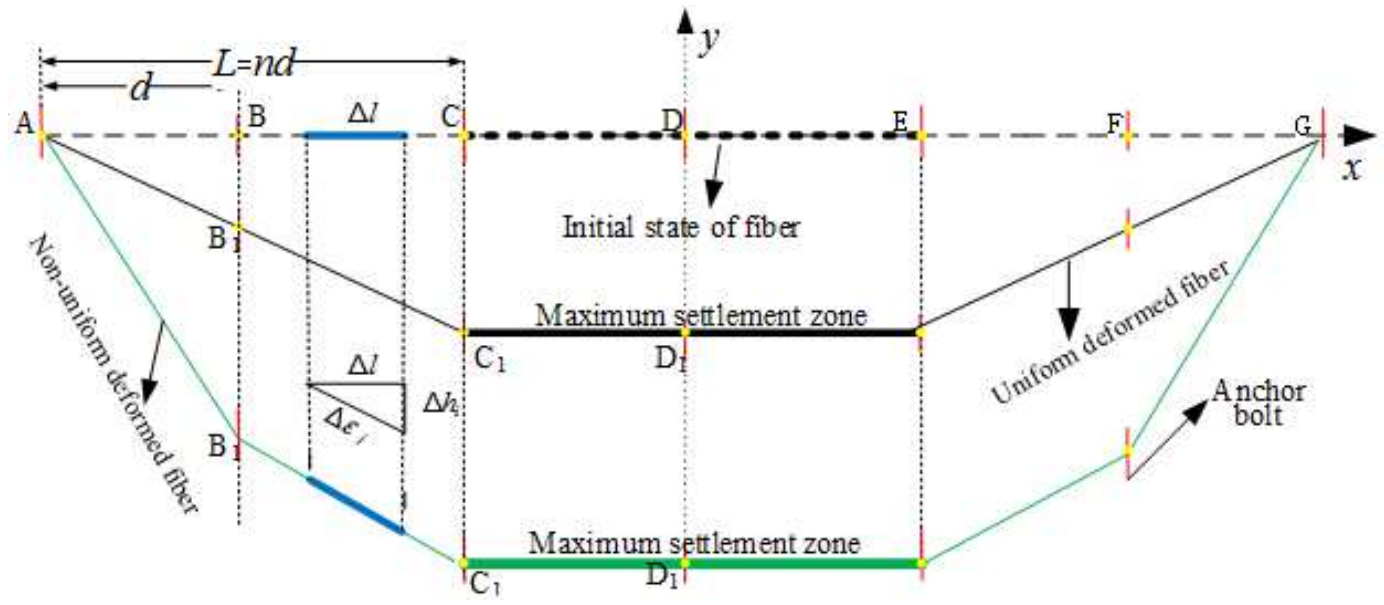

Figure 6. Quantitative characterization diagram of fiber strain for trapezoidal settlement displacement of roof: black solid line indicates that the optical fiber is uniformly stretched in a straight line; green solid line indicates that the optical fiber is subjected to uneven tension and presents a trapezoidal polygon deformation.

In order to verify the effectiveness and feasibility of quantitative characterization of roof displacement by optical fiber strain, the indoor experimental study on quantifying roof settlement displacement by fiber strain is carried out through indoor fixed-points tensile test and indoor roof settlement simulation model experiment based on POFLF and DOFS.

\section{Indoor Experiments on Pre-stretched Optical Fiber Layout at Fixed-points}

\subsection{Geometric Deformation Experiment of Pre-stretching Optical Fiber Layout at Fixed Points}

\subsubsection{Optical Fiber Tensile Test for Simulating Sporadic Roof Caving}

Because the maximum displacement point of roof subsidence of sporadic caving coal block is only one anchorage point, this paper used a fixed point vertical tensile to carry out fiber strain monitoring test.

On the test bench, a $4 \mathrm{~m}$ long $0.9 \mathrm{~mm}$ polyurethane tight sleeve optical fiber was pre-stretched, and the two ends of the optical fiber were bonded with epoxy resin and fixed on the surface of the test bench. The optical fiber was stretched vertically in the middle of the optical fiber, and the fiber deformation was a triangle with increasing vertical height, as shown in figure 7. AV 6419 of BOTDR was used as the test instrument. The test parameters are $1 \mathrm{~m}$ spatial resolution and $0.05 \mathrm{~m}$ sampling resolution. The fixed-points stretching step is $1 \mathrm{~mm}$. The fiber strain test results are shown in figure 8 .

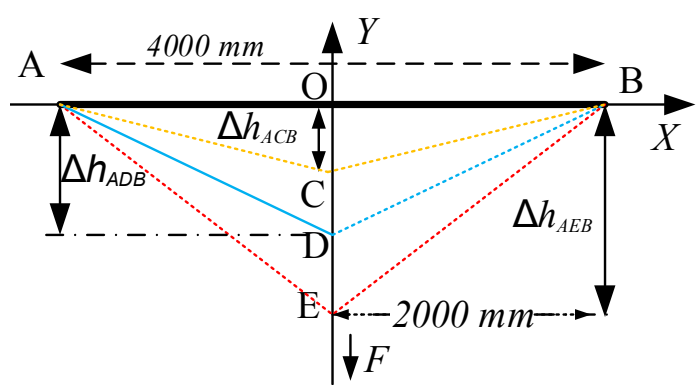

Figure 7. Experimental diagram of single point tensile deformation of fixed length fiber.

It can be seen that the fiber strain curve of "point" settlement formed by sporadic roof caving is a single peak curve. The vertical displacement of the tensile point in the middle of the optical fiber is obtained by using formula (5) at each stage of stretching distance. As shown in Figure 9. The results are in accordance with the theoretical analysis of "point" settlement deformation of roof. 


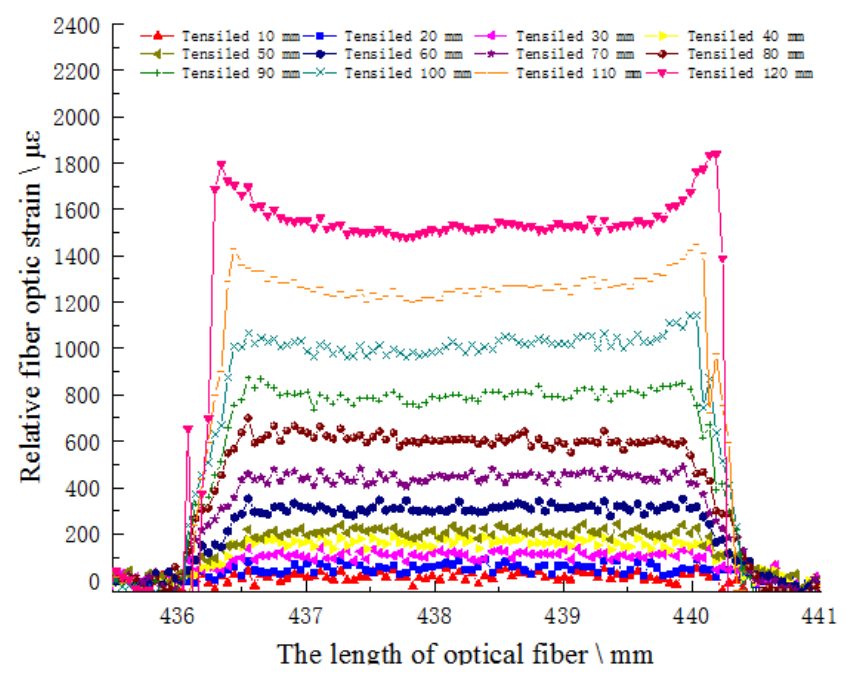

Figure 8. Fiber optic strain curve of optical fiber tensile test at a single fixed point.

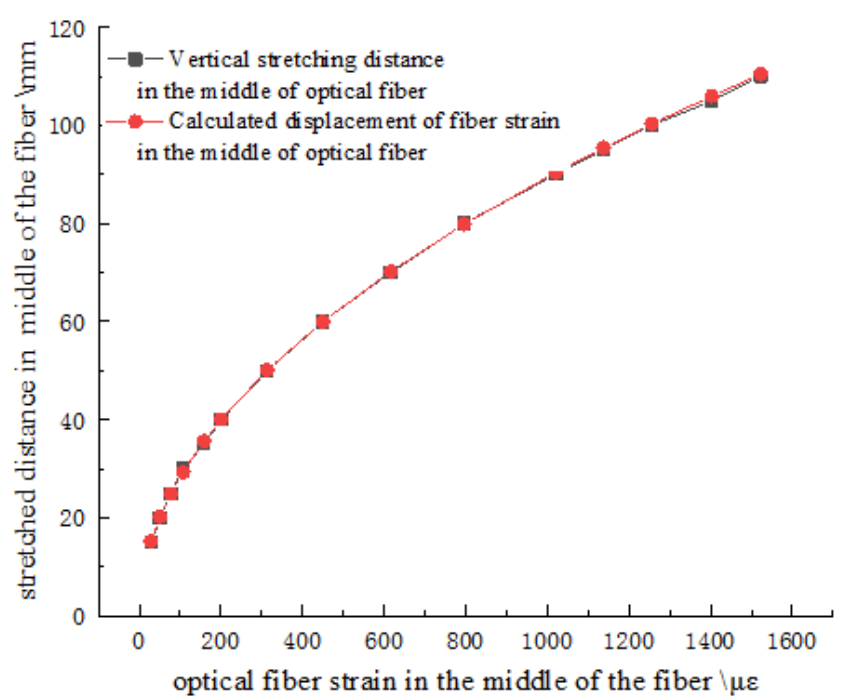

Figure 9. The comparison curve between the actual stretching distance at the midpoint of optical fiber and the maximum displacement calculated by fiber strain calculation.

From figures 8 and 9, it can be seen that under the point settlement mode formed by sporadic roof caving, the change of optical fiber strain can not only reflect the range of optical fiber deformation, but also qualitatively and quantitatively characterize the displacement of optical fiber deformation. It can be verified that it is feasible to characterize the roof subsidence displacement by the strain change of fixed-point optical fiber when the roof is sporadic caving.

\subsubsection{Optical Fiber Tensile Test on Large Zone Integral Settlement of Roof}

The test platform and principle are the same as above. A metal cuboid was used to simulate the zone of the settlement roof. The specific test process was as follows: the $4000 \mathrm{~mm}$ long $0.9 \mathrm{~mm}$ polyurethane optical fiber was pre stretched, and then both ends were fixed on the test platform with epoxy resin adhesive; The middle part with a length of $1000 \mathrm{~mm}$ was fully bonded to the lower part of the side of a sliding metal cuboid in the same way. The metal cuboid simulated the settlement deformation of a large area of integral roof. The actual test diagram and test process diagram are shown in Figure 10 below. In this way, the metal cuboid adhesive optical fiber became a section of optical fiber with no strain change.

In the experiment, the optical fiber was glued to the side of the rectangular metal body after pre stretching, and the metal block was pushed parallel to the initial position of the optical fiber and away from the initial optical fiber position by using a fixed step distance, that is, the movement direction of the metal cuboid is perpendicular to the initial layout direction of the optical fiber. With the gradual push of metal cuboid, the optical fiber presents isosceles trapezoid geometry deformation, as shown in figure 10. The fiber strain curve is shown in Figure 11 below, which consists of two single peak strain curves. The range of the metal cuboid is the non-strain varying fiber segment between two single peak strain curves.

The strain test results of the optical fiber platform geometric tension are in accordance with the theoretical analysis of the large-area overall settlement deformation of the roof, which is composed of two strain peak curves, and the middle of the two single peak curves is the initial strain free interval. According to formula (5), the settlement displacement of the tension platform in the strain section without optical fiber is calculated by the actual test strain curve, as shown in figure 12 .

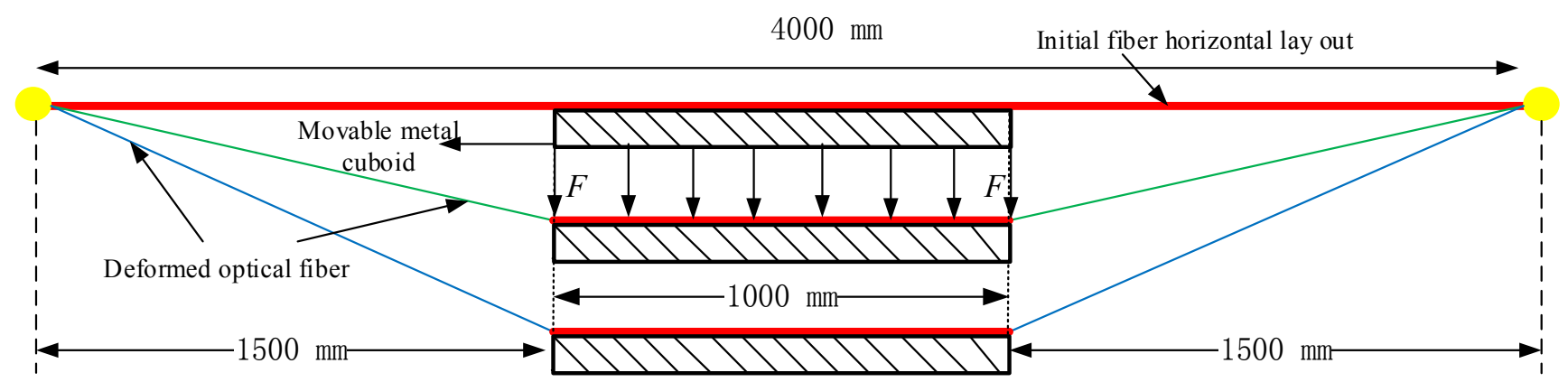

Figure 10. Tensile strain test of optical fiber in large area of roof falling. 


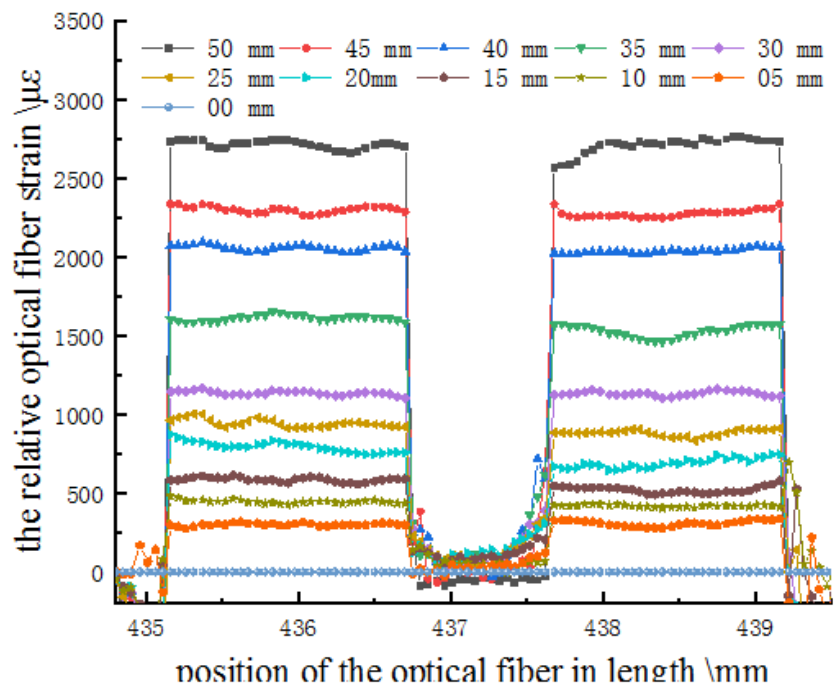

Figure 11. Optical fiber strain curve of overall roof settlement.

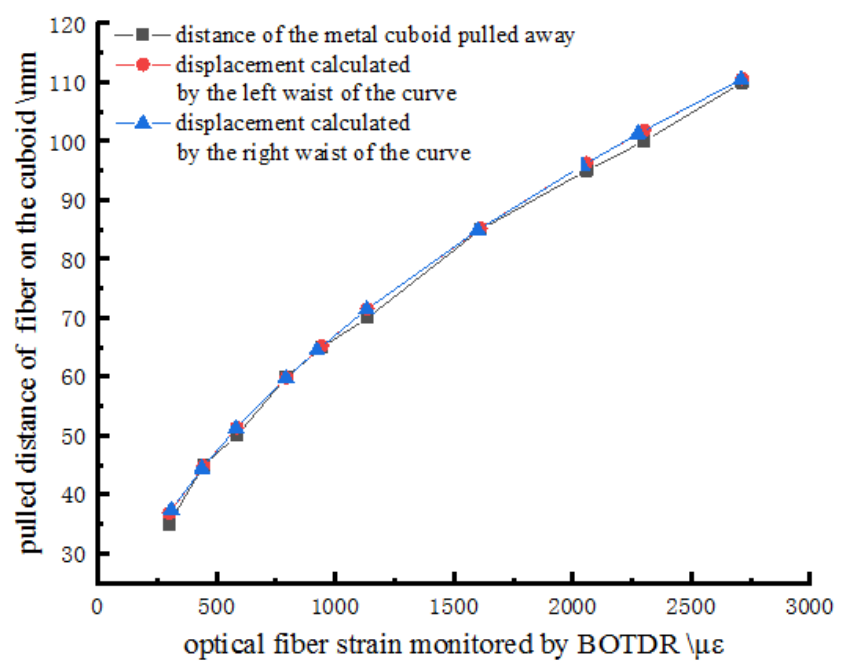

Figure 12. Comparison curve of large-scale overall settlement displacement of roof.

It can be seen from the figure that the pushing distance of the rod and the maximum displacement of the optical fiber platform represented by the fiber strain segments on the left and right sides are highly consistent, which indicates the correctness of the trapezoidal deformation theoretical analysis It can be seen that the fiber-optic strain curve of large-scale platform settlement can not only reflect the range of roof settlement, but also qualitatively and quantitatively characterize the platform settlement displacement.

On the basis of the above optical fiber linear uniform tensile test at a fixed-point, the model test of simulating roof settlement with pre-stretching optical fiber horizontal layout at fixed-points was carried out, in the experiment, the optical fiber was in polygon deformation. The fixed-points of the optical fiber is laid on the simulated roof, and the fiber is formed into polygon deformation under the action of fixed-point settlement deformation. The actual roof deflection measurement and the maximum roof settlement displacement quantified by the fiber-optic strain are measured finally, the feasibility of quantitative characterization of roof uneven settlement displacement by optical fiber strain are verified.

\subsection{Model Test on Roof Settlement of Pre-stretched Optical Fiber Layout at Fixed-Points}

In the experiment, the equal density board (EDB) is used to simulate the roof, and the screw is used to fix the optical fiber to the EDB. When the roof settlement is deformed, the deflection value of the roof is measured by the dial indicator, and the settlement displacement of the roof is calculated according to the strain change of the optical fiber layout at the fixed points of the screw, and the deflection and displacement are compared. Finally, the feasibility of the roof settlement displacement measurement through optical fiber layout at the anchor bolt (cable) fixed-points are determined.

\subsubsection{Experiment Configuration}

The indoor experiment configuration is shown in figure 13 . The screw rods simulating rock bolts were equidistant fixed on the EDB with fixed support at both ends. The pre-stretched optical fiber was laid out at fixed points at the end of the screw. The load was applied onto the middle of the board step by step to make the board settle and bend. When the EDB was bent, the corresponding screw rods also subsidence. Because the fiber between two fixed points is straight-line deformation, and the screws have the different displacement, so the fiber between multiple fixed points is polygonal deformation. At this time, the deformation section of the whole optical fiber was approximately triangular polygon deformation. By monitoring the axial strain of the optical fiber fixed at screw rods during the loading process, the maximum displacement of the roof was calculated by formula (5).

The DOFS techniques adopted in the indoor experiment is Brillouin optical frequency domain analysis (BOFDA) technology, the detailed introduction of BOFDA can be referred to the reference [10], [21]. The optical fiber strain test was carried out with the German BOFDA instrument fTB2505. The parameters of BOFDA are: $20 \mathrm{~cm}$ spatial resolution; $5 \mathrm{~cm}$ sampling resolution; $10.7-11.7 \mathrm{GHz}$ frequency scanning range; $0.05 \mathrm{MHz} / \mu \varepsilon$ of strain coefficient and 1.467 of the refractive index.

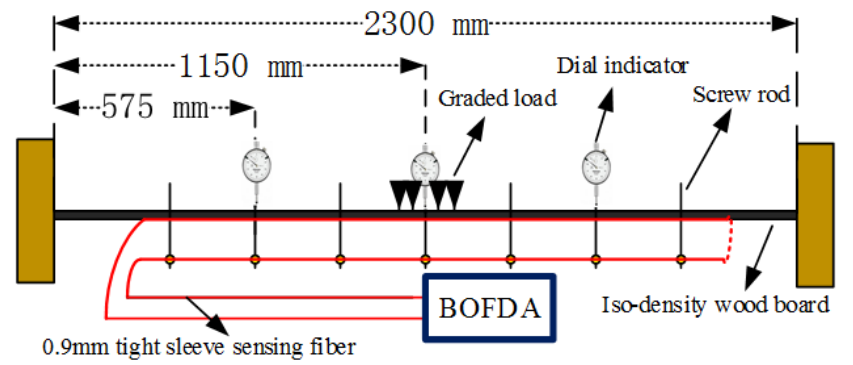

Figure 13. Indoor model experiment of the roof displacement based on POFFL and DFOS.

Because the optic strain and geometric deformation were considered only, the influence of mechanical and physical properties of EDB on the simulated roof deformation was ignored in the experiment. Although the bending deformation of EDB is slightly different from engineering practice, the 
principle of strain measurement for polygonal deformation of optical fiber at fixed-points is consistent. The strain change of optical fiber fixed by screw rods and the deflection of the EDB were measured. The detailed experiment arrangement is shown in figure 14.

1) The length of the simulated roof of the EDB was 2300 $\mathrm{mm}$, which was fixed at both ends, shown as figure 14a;

2) Long screw rods were used to simulate the anchor bolts. In the middle of the roof width, the holes were drilled at an equal distance of $300 \mathrm{~mm}$ in the length direction of the roof, and the screw rods with fixed length were penetrated, as

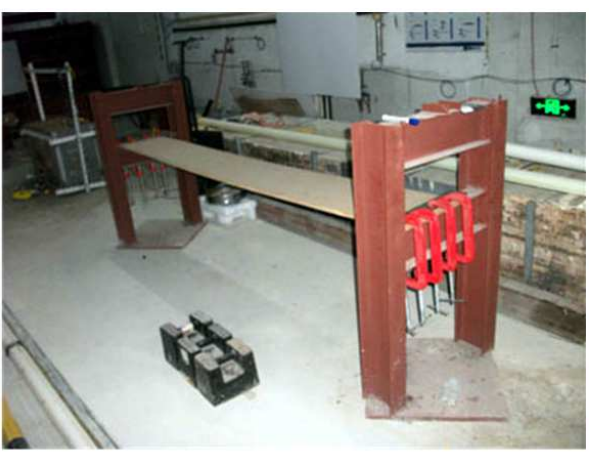

(a)

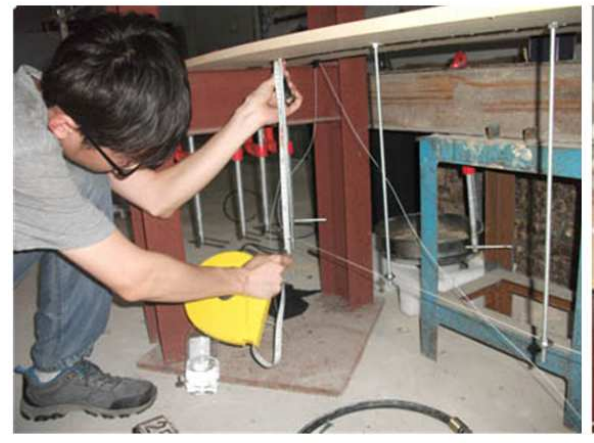

(c) shown in figure $14 \mathrm{~b}$;

3) Cutting off a certain length of $0.9 \mathrm{~mm}$ polyurethane tight sleeve optical fiber, in which half of the length of the optical fiber is pre stretched with nuts and gaskets and fixed at the lower end of the bolts, as shown in figure 14c. Epoxy resin adhesive was coated on the nuts and gaskets to increase the cohesion of optical fiber and gasket;

4) Dial indicators were installed to monitor the vertical displacement of the board in the middle of the board and 0.25 board length from both ends, as shown in figure $14 \mathrm{~d}$.

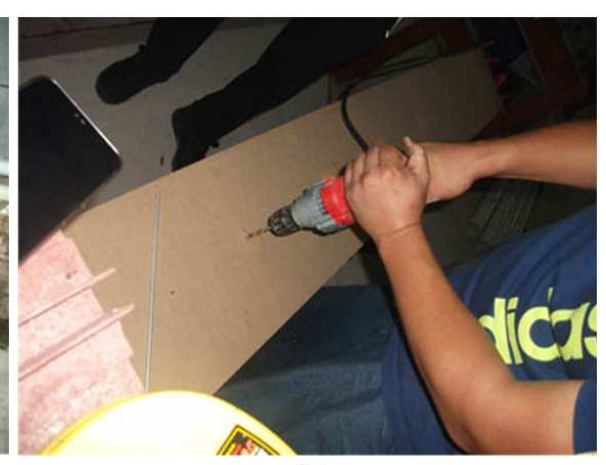

(b)

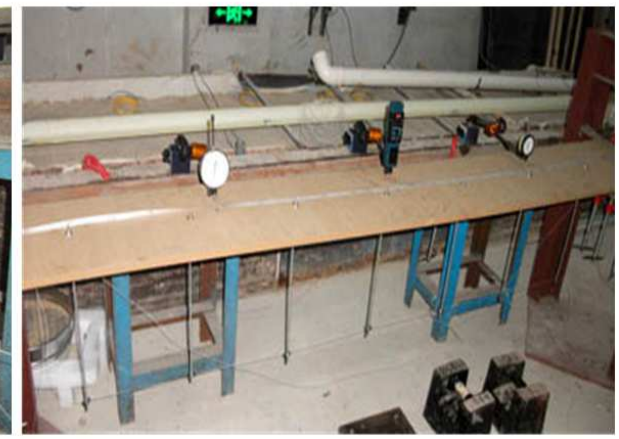

(d)

Figure 14. Layout of roof settlement simulation test; (a) wood board fixed at both ends; (b) Drilling holes on the board for installing the screw rods; (c) Fixing and laying out the optical fiber; (d) Dial indicators were installed.

\subsubsection{Experiment Processes}

Before increasing the load on the roof, BOFDA analyzer connected the two ends of the optical fiber fixed by the screw through the optical fiber jumper, so that the whole fiber became a loop, and the initial value of the optical fiber strain was tested as the initial strain; at the same time, the initial readings of the three dial indicators for testing displacement were read too.

In the middle of the roof length direction, the load was increased step by step. The initial load was $20 \mathrm{~N}$, and gradually increases to $30 \mathrm{~N}, 40 \mathrm{~N}, 50 \mathrm{~N}, 60 \mathrm{~N}, 70 \mathrm{~N}$, and $80 \mathrm{~N}$. Each time the load was increased, the roof would bend and sink under the action of the overlying load; after the roof was stationary for a period of time, the strain test was carried out with BOFDA, and then the dial indicators readings were recorded. After that, the load was loaded step by step to carry out the next measurement test. The measured optical fiber strain value after the load step-by-step increased subtracted the initial strain, the fiber-optic relative strain curve under the graded load was obtained. In this indoor simulation test, the deflection of the roof monitored by the dial indicators was the real test result in the test, which truly reflected the deflection of the roof. In this paper, it was taken as the measured value or theoretical value.

\subsubsection{Distribution of Optical Fiber Strain Curve Measured by $B O F D A$}

In this paper, the normal strain is defined as tensile strain. The optical fiber strain measured by BOFDA showed a positive strain, and the strain increased with the gradual increase of load. Figure 15a shows the original strain curve of optical fiber test; Figure 16b shows the relative strain curve of optical fiber under graded load by subtracting the initial strain of BOFDA test from the fiber strain data of each test. 


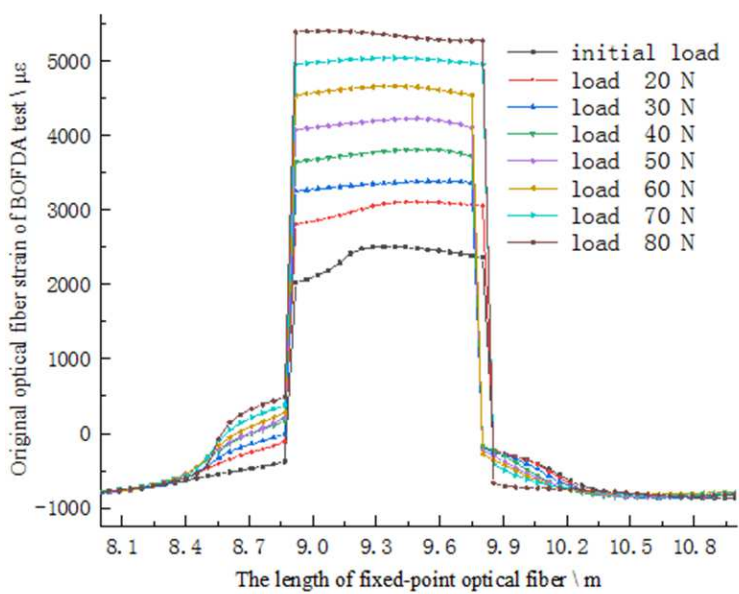

(a)

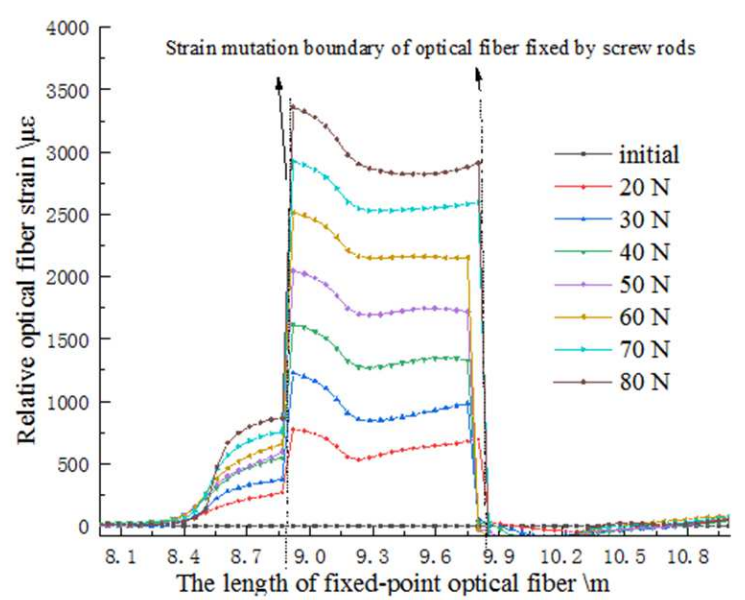

(b)

Figure 15. The optical fiber strain curves of the experiment; (a) the tested original strain; (b) the relative optical fiber strain curve.

The absolute and relative strain of optical fiber presents obvious positive tensile strain curve, and the abrupt section presents different tensile strain curve platform; with the increase of graded load, the tensile strain platform rises obviously, and they have a positive linear relationship with load.

\subsubsection{Analysis of Measured Results of Roof Deflection}

The test results show that with the continuous increase of the load at the central position of the roof, the bending curvature of the roof gradually increases, and the deflection of the middle point of the roof increases continuously. The deflection of the roof measured by the dial indicator is shown in figure 16, which shows that the deflection of the roof and the graded load are basically in a positive linear relationship.

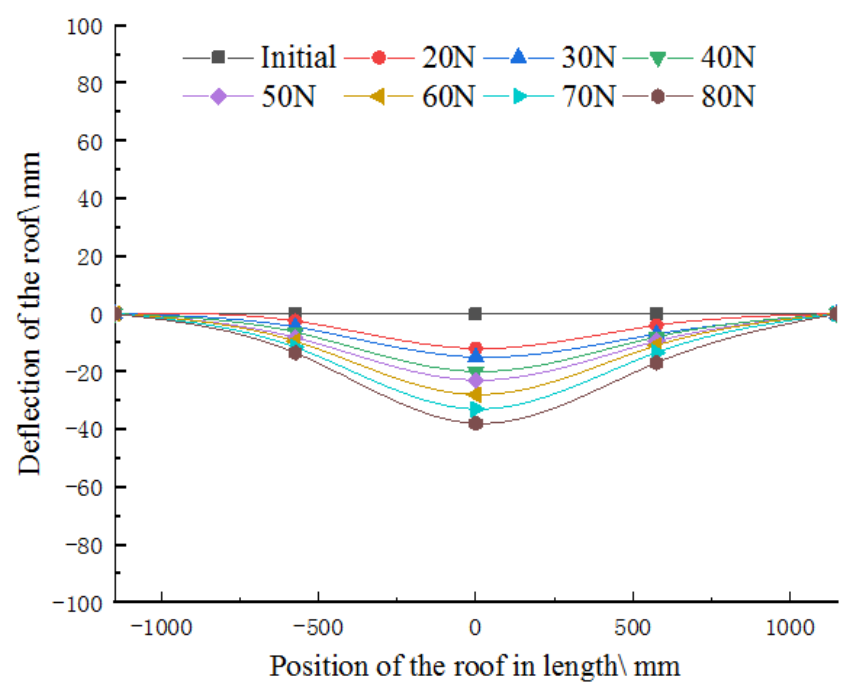

Figure 16. Roof deflection measured by dial indicators.

It can be seen from figure 16 that the deflection of the roof has a positive linear relationship with the load, and increases gradually with the increase of the load, while the strain of the optical fiber has a positive linear relationship with the graded load. It shows that there may be a positive correlation between the strain of the optical fiber and the deflection of the roof. The tensile strain of the optical fiber laid on the roof increases with the increase of the roof deflection. This demonstrate that the strain distribution of optical fiber laid out on the roof by POFLF can correctly qualitatively charecrize the roof settlement displacement.

\subsubsection{Roof Settlement Displacement Quantitatively Characterized by Optical Fiber Strain}

The range of roof settlement is obtained by the length of abrupt section of optical fiber strain, which was measured by BOFDA. Since the deformation of the optical fiber fixed by the screw rods was in polygon, the roof settlement displacement quantified by the strain of the optical fiber laid out and fixed at the screw rods can be directly obtained by formula (5). The quantitative roof displacement result of optical fiber strain is shown in figure 17a. The displacement of the mid-point of the roof under different loads is compared with the measured deflection of the dial indicators, as shown in figure $17 \mathrm{~b}$.

It can be seen that the roof settlement displacement quantified by the distributed fiber strain was consistent with the roof deflection measured by the dial indicators when the pre-stretched optical fiber was deployed at fixed points through the screw rods. It can be seen when the optical fiber arranged by screw was polygonal deformation with roof deformation, the optical fiber strain curve in deformation section not only reflect the range of roof deformation in real time, but also reflect the maximum bending deflection of roof, that is, roof settlement displacement. At the same time, it also verified the theoretical analysis of fiber polygon settlement displacement in uneven roof settlement. 


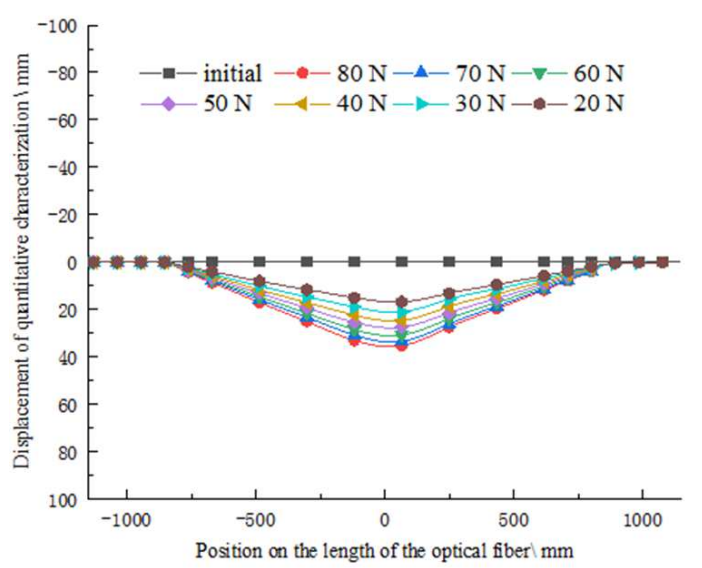

(a)

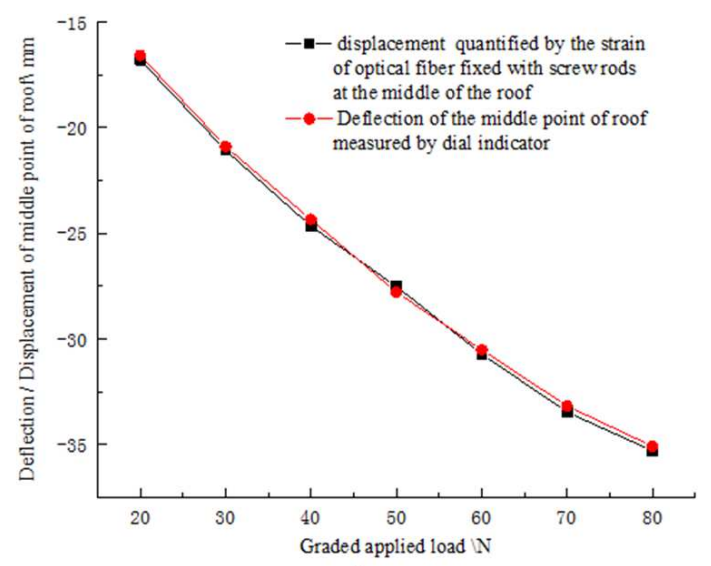

(b)

Figure 17. The displacement curve quantified by the optical fiber strain: (a) optical fiber strain quantitatively characterized roof displacement; (b) Comparison curve of the displacement calculated and the deflection measured by dial indicators.

\section{Field Monitoring of the Roadway Roof Displacement Based on POFLF and BOTDR}

The longwall fully mechanized top coal caving technology is adopted to mine 15 coal seam with an average thickness of $7.31 \mathrm{~m}$ in a working face of a coal mine, China. The direct roof is mudstone with an average thickness of $1 \mathrm{~m}$, and the basic roof is $12.5 \mathrm{~m}$ thick hard $\mathrm{K} 2$ limestone. The overburden is mainly composed of various hard sandstone strata. Roof management adopts comprehensive caving method.

The position of 998 rows of $\mathrm{W}$ steel strips is the open-cutting of the working face, and the stopingline is located at 50 rows of $\mathrm{W}$ steel strips. According to the gateroad strike, the optical cables were fixed at an interval of $1 \mathrm{~m}$ between Point A (424 rows of W steel strips) and Point B (698 rows of W steel strips) of the roof via the exposed ends of the corresponding anchor cables as fixed points. The total monitoring length is $274 \mathrm{~m}$, as shown in figure 18 .

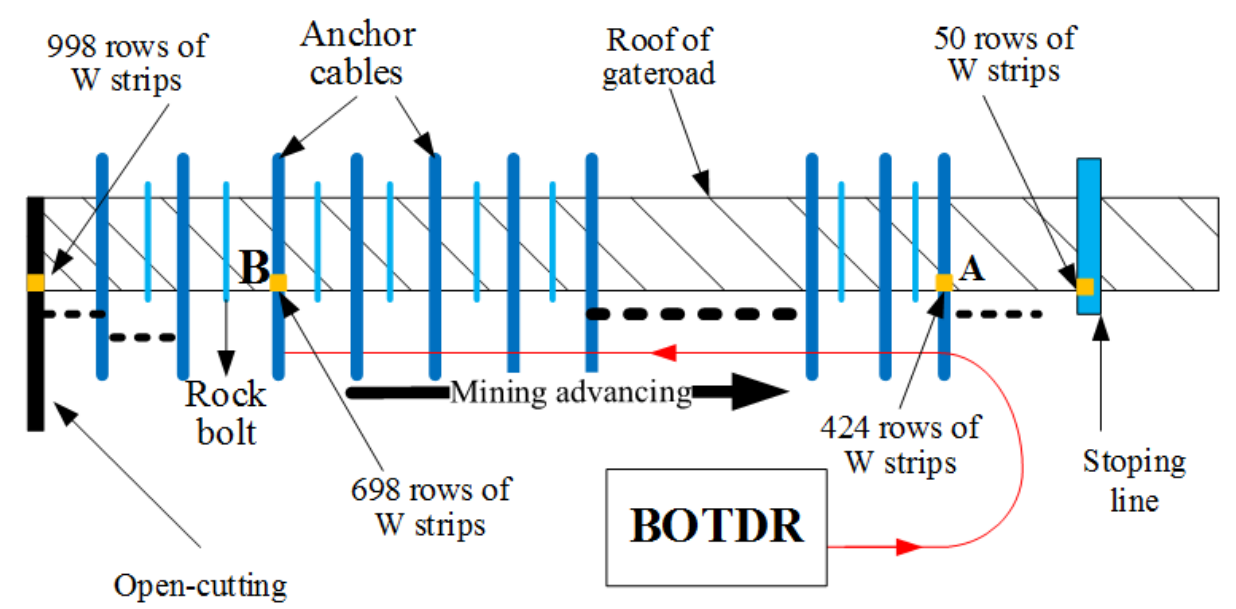

Figure 18. Layout of the distributed roof settlement monitoring of in the 150313 working face.

\subsection{Selection of Sensing Optical Fiber and Setting Parameters of BOTDR in the Field Experiment}

With the influence of the excavation and working face advancing, the roof of coal roadways is often in an unstable state of plastic failure, and the coal seam on the roof surface is seriously broken, which often leads to uneven, regional and sudden settlement. Therefore, the high-strength $5 \mathrm{~mm}$ Steel Strand (SS) cables were selected to avoid the risk of being broken by fractured coal rocks in the field experiment, the detailed introduction of the SS optical cables can be referred to the reference [21-22]. The single end mode testing BOTDR analyzer av6419 was used in the field experiment for optical fiber strain data collection and strain data processing and analysis.

\subsection{POFLF of Coal Roadway Roof in 150313 Working Face in Yinying Coal Mine}

When laying out, the optical fiber laid at fixed points between bolts (cables) shall be kept as horizontal as possible. The specific laying processes of optical cables along the roof are as follows:

(1) Selecting the monitoring area and initial laying out of optical cable; (2) Fixing the fixture to the exposed end of the 
anchor cables with anchor cable locks; (3) Fastening clamps with the optical cable tightly compressed to the tray of the fixture; (4) Adjusting the screw and anchor lock and pre-stretching the fixed cable horizontally; (5) Testing the passing path of the optical fiber; later fusing the SS optical cables with the common telecom optical cables; finally laying out the telecom cables to the main roadway's observation where it was connected to the BOTDR av6419. The complete optical fiber layout is shown in figure 18 .

\subsection{Field Monitoring of Roof Displacement}

Only the roof monitoring during mining retreating was studied in the paper. The roof displacement monitoring test of optical fiber strain quantification began on June 1, 2019, at this time, the distance between the open-cutting and the fixed point B of 698 rows W steel strip is $300 \mathrm{~m}$. in the meantime, the optical fiber strain was initialized again, and applying the simple ways to encrypt the measuring points of cross observation method (COM).

Because the spacing of the original designed roof separation instrument is $50 \mathrm{~m}$, it is difficult to monitor the roof deformation timely and accurately. In order to verify the BOTDR monitoring of roof subsidence by POFLF, COM stations and measuring points were set up every $1 \mathrm{~m}$ from point $A$ to point $B$ by using simple COM.

The principle of simple COM is the same as the traditional com measurement method, but the latter uses permanent pegs as monitoring points [23]. In this simple COM method, the stable exposed ends of rock bolts or anchor cables were used as temporary measuring points, and a total of $270 \mathrm{COM}$ measuring stations were established.

In the actual measurement of roof displacement using COM, it is assumed that there is none the vertical displacement of coal pillar and coal wall. Like the convergence measurement of roof and floor [24-25]. In the early stage, COM was used to measure the initial settlement displacement of the roof, later the COM stations were measured when the corresponding points of fiber optic strain varied anomaly. When the working face was close to point B of the test optical cable, special personnel was arranged to synchronously measure the roof displacement with relative COM every day along with the optical fiber strain monitoring.

Through the in-situ BOTDR fiber strain test in the coal mine, the results showed that the displacement of roof settlement characterized by optical fiber strain by formula (4) or (5) was consistent with that measured by COM. At the same time, it showed that the strain distribution of the $5 \mathrm{~mm}$ steel strand cable laid out horizontally at fixed points through the anchor cables of the coal roadway roof can not only reflect the range of roof settlement deformation, but also qualitatively reflect the damage degree of roof subsidence and quantitatively characterize the settlement displacement of coal roadway roof.

When the 150313 working face started mining, we began to use BOTDR to collect the optical fiber strain data, and at the same time, we carried out the simple COM roof displacement measurement according to the needs. From
June 1, 2019 to August 31, 2019, a total of 3 months of on-site monitoring of coal roadway roof settlement displacement has been carried out. After August 31, because the working face has been mined to the position where the optical cable located, the coal mine needs to recover the anchor rods and anchor cables on the roof in the coal roadway for roof caving, and the field test has to be ended.

The field test fully demonstrate the feasibility and validation of monitoring roof displacement and deformation by POFLF technology. The technology can not only monitor the settlement displacement of coal roadway roof, but also has important reference significance for other similar structures, such as tunnel roof, bridge and so on.

\section{Conclusions}

In this paper, through the theoretical analysis, indoor optical fiber strain experiment, and the field settlement displacement monitoring of coal roadways roof in q working face of a Coal Mine based on DOFS and POFLF technology, some conclusions are achieved as follows.

(1) Under the influence of plastic failure on the roof strata of coal roadways supported by bolts, two kinds of regional failure forms are often formed, that is sporadic caving and large area overall settlement.

(2) For the roof deformation of coal roadways, pre-stretched optical fiber can be fixed-point layout through the exposed end of the existing roof rock bolts or anchor cables. On the one hand, it ensures the survival rate of the optical fiber cables, on the other hand, it ensures the coupling deformation between the optical fiber cables and the corresponding roof.

(3) By laying out optical fiber horizontally via POFLF technology along the strike of rectangle coal roadways roof, when the roof subsidence occurs, fiber optic strain can be used to qualitatively and quantitatively characterize the subsidence and displacement of roof.

(4) It is feasible and validated to quantify the roof displacement by means of fiber optic stain as a supplementary or auxiliary resorts in roof safety monitoring, which is based on DOFS and POFLF. It is helpful to realize the distributed settlement displacement monitoring of coal roadways roof underground, which plays a great role in preventing coal mine roof falling and ensuring the safety production of coal mine.

\section{References}

[1] Tong R, Zhai C, Jia Q, et al. "An interactive model among potential human risk factors: 331 cases of coal mine roof accidents in China", International journal of environmental research and public health, 2018, vol. 15, no. 6, pp. 1144-1164.

[2] Shen B. "Coal mine roadway stability in soft rock: a case study “. Rock Mechanics and Rock Engineering, 2014, vol. 47, no. 6, pp. 2225-2238. 
[3] Zhao Y, Zhang N, Si G. "A fiber Bragg grating-based monitoring system for roof safety control in underground coal mining". Sensors, 2016, vol. 16, no. 10, pp. 1759-1772.

[4] HAO Deng-yun, CUI Qian-li, HE Jie, et al."Deformation characteristics and separation monitoring of layered roof roadway supported with bolts and cables", Journal of China Coal Society, 2017, vol. 42, no. S1, pp. 43-50, DOI: 10.13225/j.cnki.jccs.2016.1438.

[5] Shen B, King A, Guo H. "Displacement, stress and seismicity in roadway roofs during mining-induced failure ", International Journal of Rock Mechanics and Mining Sciences, 2008, vol. 45, no. 5 , pp. $672-688$.

[6] Hong-Pu K, Jin-Hua W, Jian L. "Study and applications of roadway support techniques for coal mines". Journal of China Coal Society, 2010, vol. 35, no. 11, pp. 1809-1814.

[7] Zhao Z G, Zhang Y J, Li C, et al. "monitoring of coal mine roadway roof separation based on fiber Bragg grating displacement sensors". International Journal of Rock Mechanics and Mining Sciences, 2015, vol. 2015, no. 74, pp. 128-132.

[8] Gong Hongkui, Mehmet S. Kizil, Zhongwei Chen, Moe Amanzadeh, Ben Yang, et al., "Advances in fibre optic based geotechnical monitoring systems for underground excavations." International Journal of Mining Science and Technology, 2019, vol. 29, no. 2 pp. 229-238.

[9] Hiroshige Ohno, Hiroshi Naruse, Mitsuru Kihara, and Akiyoshi Shimada," Industrial Applications of the BOTDR Optical Fiber Strain Sensor", Optical Fiber Technology, 2001, vol. 7 , no. 1, pp. 45-64.

[10] Hu, T.; Hou, G.; Li, Z. The Field Monitoring Experiment of the Roof Strata Movement in Coal Mining Based on DFOS. Sensors, 2020, 20, 1318.

[11] Cheung L L K, Soga K, Bennett P J, et al. Optical fibre strain measurement for tunnel lining monitoring. Proceedings of the Institution of Civil Engineers-Geotechnical Engineering, 2010, vol. 163 , no. 3 , pp. 119-130.

[12] Di Murro V, Pelecanos L, Soga K, et al. Long-term deformation monitoring of CERN concrete-lined tunnels using distributed fibre-optic sensing. Geotechnical Engineering Journal of the SEAGS \& AGSSEA, 2019, 50 (1).

[13] Ricardo Moffat, Javier Sotomayor, Juan Felipe Beltrán," Estimating tunnel wall displacements using a simple sensor basedon a Brillouin optical time domain reflectometer apparatus", International Journal of Rock Mechanics \& Mining Sciences, 2015, vol. 2015, no. 75, pp. 233-243.
[14] Naruse H, Uehara H, Deguchi $T$, et al. Application of a distributed fibre optic strain sensing system to monitoring changes in the state of an underground mine. Measurement science and technology, 2007, vol. 18, no. 10, pp. 3202.

[15] Krohn, D.; MacDougall, T.; Mendez, A. FIBER OPTIC SENSORS: Fundamental and Applications; SPIE: Bellingham, WA, USA, 2015.

[16] Hartog A H. An introduction to distributed optical fibre sensors. CRC press, 2017. pp. 9-25.

[17] Bai Q, Wang Q, Wang D, et al. Recent advances in Brillouin optical time domain reflectometry. Sensors, 2019, 19 (8): 1862.

[18] Bin S, HZ X, Dan Z, et al. Feasibility study on application of BOTDR to health monitoring for large infrastructure engineering, 2004, Chinese Journal of Rock Mechanics and Engineering. vol. 23, no. 3, pp. 494-499.

[19] Manchao H, Yubing G, Jun Y, et al. An Innovative Approach for Gob-Side Entry Retaining in Thick Coal Seam Longwall Mining, Energies, 2017, vol. 10, no. 11, pp. 1785.

[20] Kang H, Wang J, Lin J. Case studies of rock bolting in coal mine roadways. Chinese Journal of Rock Mechanics \& Engineering, 2010, vol. 29, no. 4, pp. 649-664.

[21] GY H., Tao H., ZX L., BB X., HL X., TC Z., Fiber strain characterization of "two zones" deformation of over-burden mining based on BOFDA, Journal of Mining \& Safety Engineering, 2020, vol. 37, no. 02, pp. 224-237.

[22] Hu, T.; Hou, G.; Bu, S.; Zhu, Z.; Wang, Y.; Hu, Z.; Li, Z. A Novel Approach for Predicting the Height of Water-Conducting Fracture Zone under the High Overburden Caving Strength Based on Optimized Processes. Processes 2020, 8, 950 .

[23] Zhang, G., He, F., Jia, H. et al. Analysis of Gateroad Stability in Relation to Yield Pillar Size: A Case Study. Rock Mech Rock Eng, 2017, vol. 50, pp. 1263-1278, https://doi.org/10.1007/s00603-016-1155-1.

[24] Kulatilake, P. H. S. W., et al. "Investigation of stability of a tunnel in a deep coal mine in China." International Journal of Mining Science and Technology, 2013, vol. 23, no. 4, pp. 579-589.

[25] Coons, D. J., McCarter, M. K., Wempen, J. M. et al. Experimental Evaluation of a Two-Entry Gate-Road Yield Pillar: Convergence Monitoring and Physical Properties. Mining, Metallurgy \& Exploration, 2020, vol. 37, pp. 701-708. 